\title{
Porous Ti-10Mo alloy fabricated by powder metallurgy for promoting bone regeneration
}

\author{
Wei Xu ${ }^{1,3 \dagger}$, Zhuo $\mathrm{Liu}^{2 \dagger}$, Xin $\mathrm{Lu}^{1,3^{*}}$, Jingjing Tian ${ }^{2}$, Gang Chen ${ }^{1,3}$, Bowen $\mathrm{Liu}^{1,3}$, Zhou $\mathrm{Li}^{2}$, \\ Xuanhui $\mathrm{Qu}^{1,3}$ and Cuie Wen ${ }^{4}$
}

\begin{abstract}
Porous Ti-10Mo alloys were fabricated by powder metallurgy using a space-holder method. The pore characteristics, microstructure, mechanical properties, in vitro biocompatibility, and in vivo osseointegration of the fabricated alloys were systematically investigated. The results show that with different weight ratios of the space-holder $\left(\mathrm{NH}_{4}^{-}\right.$ $\mathrm{HCO}_{3}$ ) added, all of the porous Ti-10Mo alloys sintered at $1,300^{\circ} \mathrm{C}$ exhibited a typical Widmanstätten microstructure. The porosity and average pore size of the porous structures can be controlled in the range of $50.8 \%-66.9 \%$ and 70.1-381.4 $\mu \mathrm{m}$, respectively. The Ti-10Mo alloy with $63.4 \%$ porosity exhibited the most suitable mechanical properties for implant applications with an elastic modulus of $2.9 \mathrm{GPa}$ and a compressive yield strength of 127.5 MPa. In vitro, the alloyconditioned medium showed no deleterious effect on the cell proliferation. The cell viability in this medium was higher than that of the reference group, suggesting non-toxicity and good biological characteristics of the alloy specimens. In vivo, after eight weeks' implantation, new bone tissue formed surrounding the alloy implants, and no noticeable inflammation was observed at the implantation site. The bone bonding strength of the porous $\mathrm{Ti}-10 \mathrm{Mo}$ alloy increased over time from 46.6 $\mathrm{N}$ at two weeks to $176.4 \mathrm{~N}$ at eight weeks. Suitable mechanical properties together with excellent biocompatibility in vitro and osteointegration in vivo make the porous Ti-10Mo fabricated by powder metallurgy an attractive orthopedic implant alloy.
\end{abstract}

Keywords: porosity, powder metallurgy, structure characterization, cell cytotoxicity, osteointegration

\section{INTRODUCTION}

Titanium (Ti) and some of its alloys have been widely utilized in the medical field due to their high specific strength, excellent corrosion resistance, and biocompatibility in the human body environment [1-5]. However, current widely-used $\mathrm{Ti}$ alloys, such as extra-low interstitial (ELI) Ti-6Al-4V (wt.\% hereafter), Ti-5Al-2.5Fe and Ti-6Al-7Nb, have the risk of releasing toxic aluminum (Al) and vanadium $(\mathrm{V})$ ions in vivo, which can cause health-related problems, e.g., Alzheimer's disease and neuropathy [6]. Also, the elastic modulus of these alloys $(\sim 110 \mathrm{GPa})$ is much higher than that of cortical bone (3-30 GPa) [7] and trabecular or cancellous bone $(0.02-3 \mathrm{GPa})[7]$, which results in severe stress shielding, leading to premature implant failure. Therefore, much effort has been made to develop Al-free and V-free lowmodulus biocompatible $\beta$-Ti alloys. Notable examples include the United States Food and Drug Administration (FDA)-approved proprietary alloys $\mathrm{Ti}-13 \mathrm{Nb}-13 \mathrm{Zr}$ and $\mathrm{Ti}$ $12 \mathrm{Mo}-6 \mathrm{Zr}-2 \mathrm{Fe}$, and the non-proprietary alloy $\mathrm{Ti}-15 \mathrm{Mo}$. In particular, binary $\mathrm{Ti}-\mathrm{Mo}$ alloys containing $4 \%-20 \%$ molybdenum (Mo) have received significant attention due to their simplicity and reasonable cost [8-15], as well as their ability to cause only a very low amount of artifact as seen in magnetic resonance imaging (MRI) compared with other $\beta$-Ti alloys [16].

As a commonly used $\beta$-phase stabilizing element in $\mathrm{Ti}$, Mo is non-toxic below an ion concentration of $8.5 \mu \mathrm{g} \mathrm{L}^{-1}$ [17]. It can effectively reduce the elastic modulus of the resulting Ti alloys through forming a metastable or stable

\footnotetext{
${ }^{1}$ Beijing Advanced Innovation Center for Materials Genome Engineering, University of Science and Technology Beijing, Beijing 100083, China

2 CAS Center for Excellence in Nanoscience, Beijing Key Laboratory of Micro-nano Energy and Sensor, Beijing Institute of Nanoenergy and Nanosystems, Chinese Academy of Sciences, Beijing 100083, China

${ }^{3}$ Beijing Advanced Innovation Center for Materials Genome Engineering, Institute for Advanced Materials and Technology, University of Science and Technology Beijing, Beijing 100083, China

${ }^{4}$ School of Engineering, RMIT University, Melbourne 3001, Australia

${ }^{\dagger}$ These authors contributed equally.

* Corresponding author (email: luxin@ustb.edu.cn)
} 
Table 1 Chemical composition of $\mathrm{Ti}$ and Mo powders

\begin{tabular}{|c|c|c|c|c|c|c|c|c|c|c|}
\hline \multirow[t]{2}{*}{ Powder } & \multicolumn{10}{|c|}{ Chemical composition (wt.\%) } \\
\hline & $\mathrm{H}$ & $\mathrm{C}$ & $\mathrm{N}$ & $\mathrm{O}$ & $\mathrm{Si}$ & $\mathrm{Cl}$ & $\mathrm{Fe}$ & $\mathrm{Ni}$ & $\mathrm{Ti}$ & Mo \\
\hline $\mathrm{Ti}$ & 0.02 & 0.02 & 0.04 & 0.25 & 0.02 & 0.05 & 0.06 & 0 & Balance & 0 \\
\hline Mo & 0.07 & 0.05 & 0.05 & 0.20 & 0.02 & 0.01 & 0.06 & 0.01 & 0 & Balance \\
\hline
\end{tabular}

$\beta$-phase, while increasing the strength and wear resistance [18]. Also, it can contribute to regulating the acid-base balance in the human body [19-21]. The near- $\beta$ alloy Ti15 Mo has been used in the clinic since 1998 [12]. Previous studies have proved that solid-solution hardening in Ti-Mo alloys appears to peak at 10\%-12\% Mo and that Ti-(10-12.5)Mo alloys (335-350 HV) are harder than Ti$6 \mathrm{Al}-4 \mathrm{~V}(294 \mathrm{HV})$ and Ti-13Nb-13Zr (285 HV) under the same conditions [8]. From an application-and-design point of view, a lower Mo content is always preferred. Minimizing the addition of Mo reduces the cost and the potential risk. Furthermore, reducing the amount of Mo also lowers the melting point of Ti-Mo alloys, which makes the alloys easy to process. Accordingly, the composition of $\mathrm{Ti}-10 \mathrm{Mo}$ was selected as a practical option in this study.

As mentioned above, a mismatch in elastic modulus between the implant and the bone will cause a stress shielding effect and may eventually lead to implant failure. Even though the elastic modulus of solid Ti-Mo alloys can be decreased to $\sim 65 \mathrm{GPa}$, this is still about two times greater than that of human bone $(0.02-30 \mathrm{GPa})$. Hence, to further reduce the negative influence of this incompatibility and improve the biological fixation of implants to the surrounding tissues, a porous structure is introduced to the Ti-10Mo alloy [22]. The porous structure allows new bone tissue ingrowth and can achieve bonding between the implant and the bone tissue. Additionally, an open-cellular porous structure in implants also provides space for body fluid transportation [23-28], which facilitates new bone tissue generation, modeling and remodeling. Several previous studies have indicated that porous $\mathrm{Ti}-(7.5-15) \mathrm{Mo}$ alloys can be processed by different techniques, such as selective laser sintering and powder metallurgy (PM) [29-32], and their salient characteristics, mainly their promising mechanical properties and corrosion resistance, make these alloys attractive candidates as an implant material. However, the in vivo osteointegration of porous Ti-Mo alloys is still rarely investigated in the literature so far, but it is crucial for their clinical use.

In this paper, porous $\mathrm{Ti}-10 \mathrm{Mo}$ alloys were fabricated by PM using a space-holder technique from hydride-dehy- dride $(\mathrm{HDH}) \mathrm{Ti}$ powder and hydrogen-reduced Mo powder. The pore characteristics, microstructure, mechanical properties, in vitro biocompatibility, and in vivo osteointegration of these porous $\mathrm{Ti}-10 \mathrm{Mo}$ alloys were systematically assessed. This study aims to establish the necessary understanding of the low-cost porous $\mathrm{Ti}-10 \mathrm{Mo}$ alloys for orthopedic implant applications and to provide the basics supporting their practical clinical applications.

\section{EXPERIMENTS AND METHODS}

\section{Materials preparation and characterization}

The HDH Ti powder and the hydrogen-reduced Mo powder (Beijing Xing Rong Yuan Technology Co. Ltd, Beijing, China) of 500 mesh $(<25 \mu \mathrm{m})$ with purity of 99.9\% were used as the raw materials for the fabrication of the binary Ti-10Mo alloy. The chemical compositions of the metal powders are listed in Table 1. The Ti-10Mo powder mixtures were blended with space-holder particles (ammonium hydrogen carbonate, $\mathrm{NH}_{4} \mathrm{HCO}_{3}$ ) for $3 \mathrm{~h}$, and then was cold-pressed into a cylindrical compact under $260 \mathrm{MPa}$. Finally, the isothermal sintering was carried out in the argon (Ar) protection environment at $1,300^{\circ} \mathrm{C}$ for $2 \mathrm{~h}$. The detailed fabricating process is available in our previous study [33].

An X-ray tomography scanning technique (nanoVoxel2000, Sanying Precision Instruments Co. Ltd, Tianjin, China) was used to analyze the internal pore structure of the specimens. After scanning, the computed tomography (CT) datasets were used to produce a series of original reconstructed slice images using a back projection algorithm. Then the slice images were input into the Avizo software to be reconstructed. The total porosity, connected porosity and average pore sizes of the specimens were calculated by Avizo, as described in our previous study [33]. X-ray diffraction (XRD) for phase analysis was conducted with a Dmax-RB X-ray diffractometer $(\mathrm{Cu} \mathrm{Ka}$, $\lambda=0.15406 \mathrm{~nm}$, Rigaku, Tokyo, Japan). A scanning electron microscope (SEM) (JSM-6480LV JEOL, Tokyo, Japan) equipped with an energy dispersive X-ray detector (EDS) was used to analyze the microstructure. Before microstructure observation, the working surface of each sample was ground, polished, and etched using the Kroll's 
etchant (5\% hydrofluoric acid, 10\% nitric acid and $85 \%$ distilled water). Compression specimens with a gauge size of $\varphi 3 \mathrm{~mm} \times 5 \mathrm{~mm}$ were cut by electric discharge machining, and the specimen surfaces were polished with $\mathrm{SiC}$ papers up to 5,000 grit. Compression testing was performed on an Instron machine at a strain rate of $2 \times 10^{-3} \mathrm{~s}^{-1}$ at room temperature. The compressive yield strength and elastic modulus were calculated from the stress-strain curves. Five specimens were tested to verify reproducibility for XRD and compression experiments.

\section{In vitro biocompatibility test}

Indirect and direct cytotoxicity tests were carried out with murine osteoblast cells (MC3T3-E1) to examine the in vitro biocompatibility of the fabricated porous $\mathrm{Ti}-10 \mathrm{Mo}$ alloy. For comparison, as-cast dense Ti-6Al-4V and CP$\mathrm{Ti}$ were studied simultaneously, which are commonly used in clinical practice. The cells were cultured in Dulbecco's modified Eagle's medium (DMEM) containing $10 \%$ fetal bovine serum (FBS), $100 \mathrm{U} \mathrm{mL}^{-1}$ penicillin, and $100 \mu \mathrm{g} \mathrm{mL}{ }^{-1}$ streptomycin at $37^{\circ} \mathrm{C}$ in a humidified atmosphere of air containing $5 \% \mathrm{CO}_{2}$. The specimens were cut into discs of $10 \mathrm{~mm}$ in diameter and $1 \mathrm{~mm}$ in thickness, and the surfaces were polished with $\mathrm{SiC}$ papers up to 5,000 grit. Then the specimens were ultrasonically cleaned and sterilized for further cytotoxicity assessment.

In the indirect testing, the specimens were placed individually in a 24-well tissue culture plate and immersed in DMEM at a ratio of $3 \mathrm{~cm}^{2} \mathrm{~mL}^{-1}$ (the surface area of the disc to the volume of media) for $24 \mathrm{~h}$ to obtain extracts. Then, the cells were incubated by the extracts and DMEM (reference group) in 96-well plates at a density of 5,000 cells per $100 \mathrm{~mL}$. At specific times (one day, two days, and three days), $10 \mu \mathrm{L}$ of 3-(4,5-dimethylthiazol-2-yl)2,5-diphenyltetrazolium bromide (MTT) solution was added to each well and was incubated for $4 \mathrm{~h}$. Then $100 \mu \mathrm{L}$ of dimethyl sulfoxide (DMSO) was added to each well, and further incubated for $5 \mathrm{~min}$. The absorbance was recorded by a multimode detector on a Synergy HT (BioTek, US) at a wavelength of $570 \mathrm{~nm}$. The cell viability ratio (CVR) was calculated by the formula given by: CVR $=\left(\mathrm{OD}_{570 \mathrm{~nm}}\right.$ in experimental extract $/ \mathrm{OD}_{570 \mathrm{~nm}}$ in control extract) $\times 100 \%$.

Based on the International Standard ISO 10993-5 [34], the cytotoxic level was categorized into six groups: 0: $\geq 100 \%$; $1: 75 \%-99 \%$; 2: $50 \%-74 \%$; 3: $25 \%-49 \%$; $4: 1 \%-$ $24 \%$; $5: \leq 1 \%$. The CVR values were analyzed using oneway ANOVA $(P<0.05)$, and the results were expressed as the mean \pm standard deviation (SD). $P<0.05$ was considered statistically significant. Five specimens were tes- ted, and the average values were obtained.

In the direct testing, MC3T3-E1 cells, at an initial density of $1 \times 10^{5}$ cells/well, were seeded on the sterilized porous $\mathrm{Ti}-10 \mathrm{Mo}$, as-cast dense $\mathrm{Ti}-6 \mathrm{Al}-4 \mathrm{~V}$ and $\mathrm{CP}-\mathrm{Ti}$ alloys in 24-well plates. The adhesion analysis of the MC3T3-E1 cells cultured with the specimens for 1 and $4 \mathrm{~h}$ was conducted to estimate the living status in the early stage. After 1, 2, and 3 days of culture, the cell cytoskeleton and nuclei were stained by phalloidin and DAPI (Sigma-Aldrich), respectively, and the morphology of the cells on the surface of each specimen was observed by a fluorescence microscope. For SEM observation, the culture medium was removed first and the cells were rinsed with phosphate buffered saline three times. Immediately after the last wash, a fixing solution ( $4 \%$ glutaraldehyde) was added to the culture wells and they were kept at room temperature for $30 \mathrm{~min}$. Once the cells were fixed, a dehydration process took place by sequential washings in $60 \%, 70 \%, 80 \%, 90 \%, 95 \%$ and $100 \%$ ethanol solutions for $10 \mathrm{~min}$ at each step. After that the specimens were gold-coated and observed by SEM.

\section{Mo ion release}

To examine Mo ion release, Ti-Mo specimens were immersed in DMEM containing $10 \%$ FBS, $100 \mathrm{U} \mathrm{mL}^{-1}$ penicillin, and $100 \mu \mathrm{g} \mathrm{mL}^{-1}$ streptomycin at $37^{\circ} \mathrm{C}$ in a humidified atmosphere of air containing $5 \% \mathrm{CO}_{2}$ for 1,2 , 3,5 , and 7 days at a ratio of $3 \mathrm{~cm}^{2} \mathrm{~mL}^{-1}$ (the surface area of the disc to the volume of media). The Mo ion concentration in the solution was analyzed by an inductively coupled plasma spectrometry (PerkinElmer, Optima 5300 DV).

\section{Animal experiment}

Adult male Sprague-Dawley (SD) rats of 200-250 g in weight from Academy of Military Medical Sciences were kept at $25^{\circ} \mathrm{C}$ with free access to food and water for three days before surgery. All surgical procedures were done under a strict aseptic protocol. The rats were anesthetized by an intraperitoneal injection of $1 \%$ (wt.\%) pentobarbital (Merck, Germany) solution, $10-12.5 \mathrm{~mL} \mathrm{~kg}^{-1}$. The knee joint region was scrubbed with a tincture of iodine and $75 \%$ ethanol and shaved subsequently. Then the animal was given a local anesthetics of $0.5 \%$ (wt.\%) lidocaine solution by infiltration anesthesia to the periosteum. A hand drill with a screw rod of $1.3 \mathrm{~mm}$ diameter and $10 \mathrm{~mm}$ length was used to drill a hole through the cortical bone, trabeculae and bone marrow located at the distal femur. Individual porous $\mathrm{Ti}-10 \mathrm{Mo}$ rods were pressed into the pre-drilled holes in the right femurs. The diameter 
and length of the implanted specimens were $1.3 \pm$ $0.05 \mathrm{~mm}$ and $3 \pm 0.05 \mathrm{~mm}$. The specimen was always implanted into the left limbs. The animals were received an intramuscular injection of clavulanate-potentiated amoxicillin in the first three days and were inspected daily for clinical signs of complications or adverse reactions. The rats were allowed unrestricted cage activity postoperatively. No attempt was made to limit their activity after surgery. The animal experiment was performed at the Beijing Institute of Nanoenergy and Nanosystems, in accordance with the animal ethics approval and guidance of the Animal Research Committee of the Institute.

After survival periods of two, four, and eight weeks, the rats were euthanized. Six rats were sacrificed at every time point, and the distal pieces of each femur, spanning $5 \mathrm{~mm}$ in length and containing the Ti-10Mo alloy rod, were obtained. Then the six specimens were observed by micro-CT (Quantum GX, PerkinElmer). After that, three specimens were used for histological analysis, and the other three specimens were utilized for biomechanical analysis.

For a hard-tissue slicing experiment, the specimens were dehydrated in a graded ethanol series ( $70 \%$ to $100 \%)$ after fixation in $10 \%$ formalin solution for two weeks. They were then embedded without decalcification in a methylmethacrylate (MMA) solution, which polymerized at $37^{\circ} \mathrm{C}$ within one week. Then, the specimens were sliced into $250 \mu \mathrm{m}$ slices using a low-speed diamond saw (Leica Microtome, Wetzlar, Germany). After that, the specimens were polished to a final thickness of about $20 \mu \mathrm{m}$ and glued to glass slides with permanent mounting medium (Fisher Scientific, USA). Finally, the specimens were stained with toluidine blue and were observed by optical microscopy and laser confocal fluorescence microscopy (Leica TCS SP8, Leica, Germany). In the laser confocal fluorescence microscopy observation, the specimens (metals) were reflected by the laser and marked as cyan. The implant sites were evaluated macroscopically in a semiquantitative manner concerning inflammation, hemorrhage, and necrosis.

For biomechanical testing, a specifically designed device was used to perform push-out testing of the porous $\mathrm{Ti}-10 \mathrm{Mo}$ alloy. The harvested bone block containing each test specimen was fixed onto the holder with resin, and the testing machine (Instron) was loaded parallel to the long axis of the test specimen at a cross-head speed of $0.5 \mathrm{~mm} \mathrm{~min}^{-1}$. The peak load was recorded as the bonding strength between the bone and the test specimen. Three specimens were tested, and the average bonding strengths were obtained.

\section{RESULTS AND DISCUSSION}

\section{Microstructure, pore characteristics, and mechanical properties}

Fig. 1 shows XRD patterns and microstructures of the Ti$10 \mathrm{Mo}$ alloys with different ratios of space-holder added. It can be seen from Fig. 1a that there were no significant differences in the XRD patterns of the fabricated porous Ti-10Mo alloys with different weight ratios of spaceholder added. The diffraction peaks of the porous $\mathrm{Ti}$ 10 Mo suggested that the alloys mainly consisted of $\alpha$ and $\beta$ phase. During the furnace cooling, $\alpha$ phase precipitated from the $\beta$ phase intracrystallinely and along the grain boundaries, leading to the formation of the Widmanstätten structure $(\alpha+\beta)$. Also, there were no diffraction peaks of elemental Mo in the as-sintered Ti-10Mo alloys.

Fig. $1 \mathrm{~b}-\mathrm{d}$ shows the microstructures of the porous Ti10 Mo alloys with different weight ratios of space-holder added. It can be seen that all the specimens exhibited uniform typical Widmanstätten structures, which is consistent with the XRD analysis. Also, as Fig. 1e-g shown, no segregation of the element Mo was discovered, indicating that Mo had completely diffused into the $\mathrm{Ti}$ matrix after sintering at $1,300^{\circ} \mathrm{C}$ for $2 \mathrm{~h}$. The pore characteristics of the porous Ti-10Mo extracted from X-ray tomography scanning, including total porosity $\left(P_{\mathrm{t}}\right)$, connected porosity $\left(P_{c}\right)$, and average pore size, are summarized in Table 2. It can be seen that, with an increase in the amount of space-holder from $35 \%$ to $55 \%$, the total porosity, connected porosity, and average pore size all increased significantly. The average pore size of the porous Ti-10Mo alloy ranged from 70 to $380 \mu \mathrm{m}$.

The mechanical properties of the Ti-10Mo alloys with different porosities were evaluated by compression testing. The engineering stress-strain curves and the mechanical properties of the porous $\mathrm{Ti}-10 \mathrm{Mo}$ alloys are shown in Fig. 2. It can be seen that the porous Ti-10Mo alloys with different porosities exhibited similar stressstrain behavior. No fractures were observed during the compression process, demonstrating the excellent elasticplastic deformation capability of the porous $\mathrm{Ti}-10 \mathrm{Mo}$ alloys. Compression tests were stopped at $50 \%$ strain for all the porous specimens. The compressive yield strength decreased from 248.2 to $69.9 \mathrm{MPa}$ as the porosity increased from $50.5 \%$ to $66.9 \%$ (Fig. 2b). The elastic modulus of the porous Ti-10Mo alloys ranged from $1.7 \mathrm{GPa}$ for the Ti-10Mo with a porosity of $66.9 \%$ to $6.4 \mathrm{GPa}$ for the $\mathrm{Ti}-10 \mathrm{Mo}$ with a porosity of $50.5 \%$. 

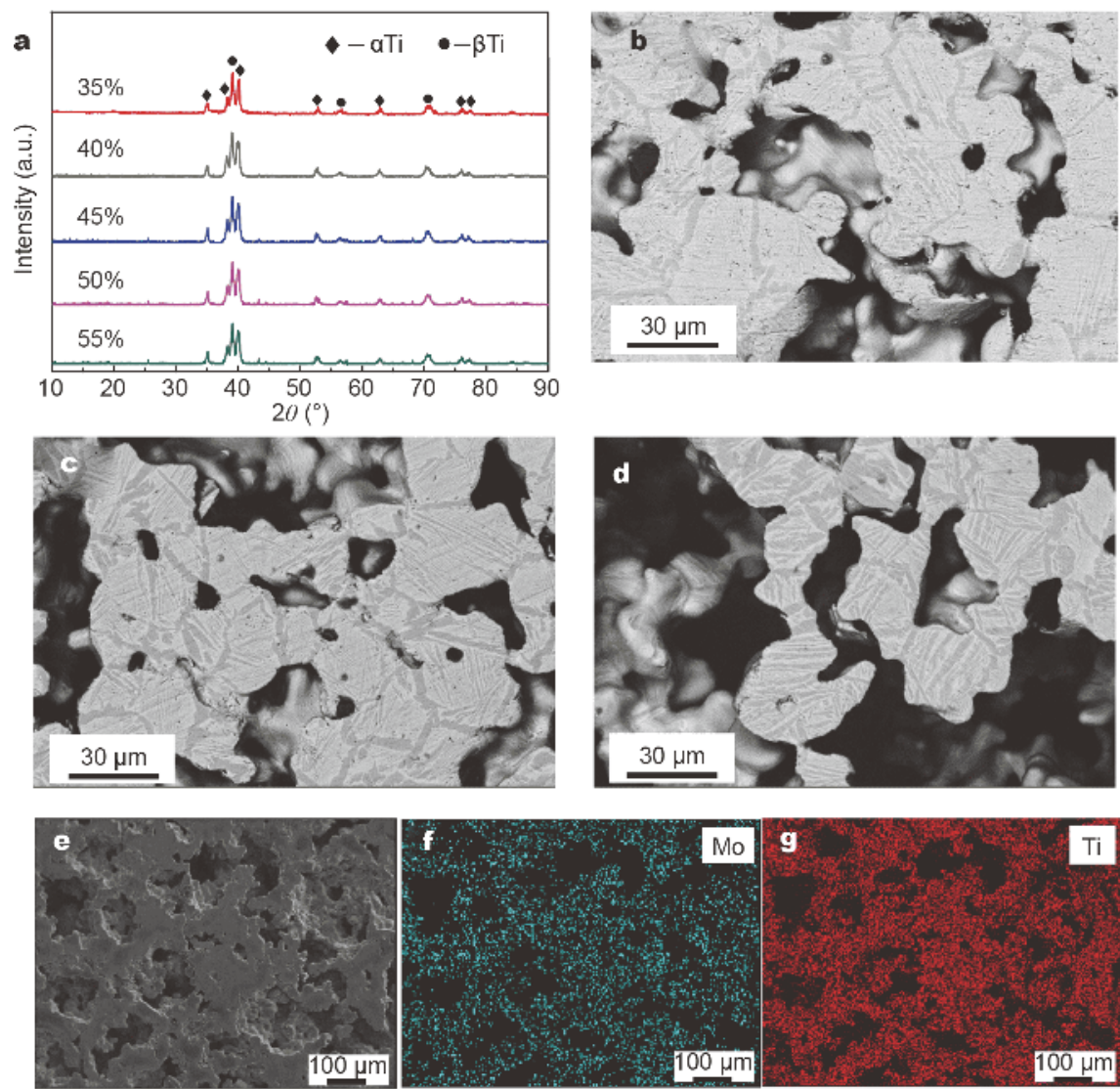

Figure 1 (a) XRD patterns, (b-d) SEM backscatter electron images showing microstructures of Ti-10Mo alloys with different weight ratios of spaceholder added: (b) 35\%, (c) 45\%, and (d) 55\%, and (e-g) SEM secondary electron image of Ti-10Mo alloy with $35 \%$ space-holder added and corresponding mapping of $\mathrm{Ti}$ and Mo elements.

Table 2 Pore characteristics of Ti-10Mo alloy with different weight ratios of space-holder added

\begin{tabular}{cccccc}
\hline Alloy & \multicolumn{5}{c}{ Ti-10Mo } \\
\hline Space-holder content (wt.\%) & 35 & 40 & 45 & 50 & 55 \\
Total porosity (\%) & $50.8 \pm 1.1$ & $54.7 \pm 1.2$ & $58.8 \pm 1.4$ & $63.4 \pm 1.5$ & $66.9 \pm 1.6$ \\
Connected porosity (\%) & $46.1 \pm 1.0$ & $50.5 \pm 1.2$ & $54.3 \pm 1.4$ & $59.1 \pm 1.4$ & $62.8 \pm 1.7$ \\
Average pore sizes ( $\mu \mathrm{m})$ & $70.1 \pm 1.6$ & $140.9 \pm 2.9$ & $241.3 \pm 5.7$ & $321.6 \pm 7.8$ & $381.4 \pm 10.1$ \\
\hline
\end{tabular}

The pore characteristics and mechanical properties are two critical factors to affect the osteogenic ability of the implant materials. It has been demonstrated that the porous structure can provide space for new bone tissue ingrowth and pathways for body fluid and nutrient transportation, thereby accelerating osseointegration of the implant, promoting bone regeneration and growth [35-37]. It is generally accepted that pores with sizes between 100 and $400 \mu \mathrm{m}$ are optimal for bone ingrowth $[38,39]$. With an addition of $40 \%$ space holder, the porous Ti-10Mo exhibited $54.7 \%$ total porosity, $50.5 \%$ connected porosity and an average pore size of $140.9 \mu \mathrm{m}$. Hence, the porous $\mathrm{Ti}-10 \mathrm{Mo}$ alloys with $54.7 \%-66.9 \%$ porosity are suitable for implant material applications regarding the average pore size. Additionally, with the suitable average pore size, the large porosity is favorable for bone osteointegration. However, the rise of porosity inevitably deteriorates the strength of the materials. Generally, the compressive yield strength of human trabecular or cancellous bone is about 2-80 MPa and the elastic modulus of ranges from 0.02 to $3.0 \mathrm{GPa}$ [7]. Results from this study indicate that the compressive yield strength of the porous $\mathrm{Ti}-10 \mathrm{Mo}$ alloy with $63.4 \%$ porosity conforms to the basic compressive mechanical property requirement of human 

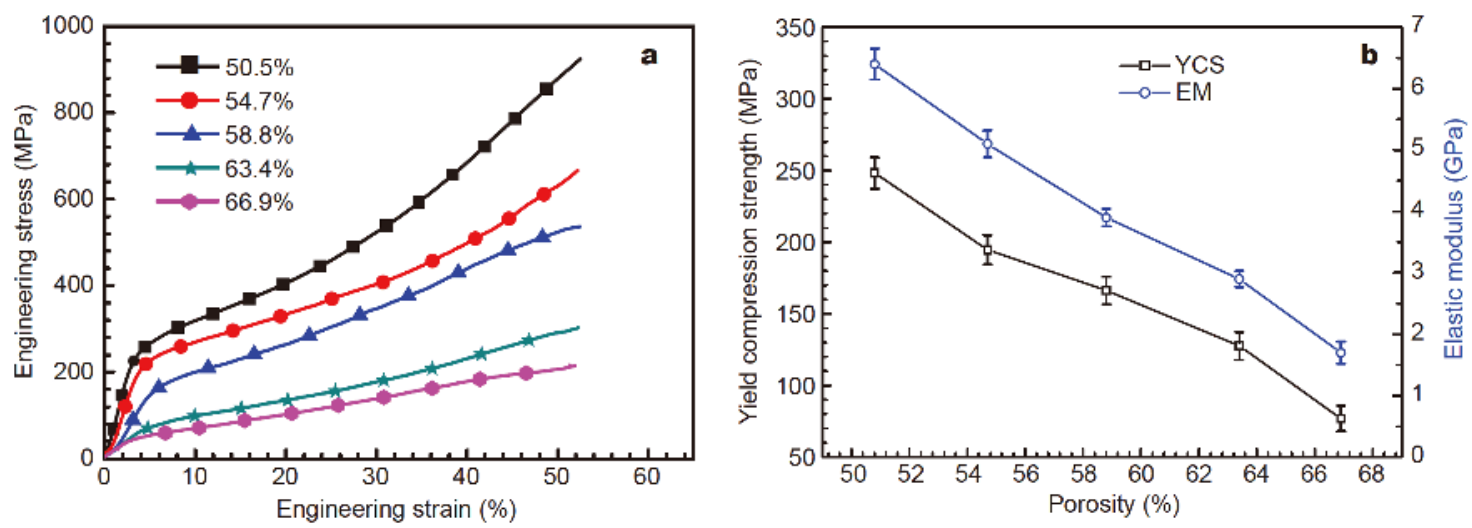

Figure 2 (a) Engineering stress-strain curves of Ti-10Mo alloys with different total porosities. (b) Influence of porosity on compression yield strength and elastic modulus of Ti-10Mo alloys.

trabecular bone and the corresponding elastic modulus is also close to that of human cancellous bone. Hence, the satisfied mechanical properties together with the suitable average pore size and larger porosity confirms that the porous Ti-10Mo alloy with $63.4 \%$ porosity can be anticipated as a promising implant material candidate. Therefore, the next section analyzes the in vitro biocompatibility and in vivo osteointegration of the Ti-10Mo alloy with $63.4 \%$ porosity.

\section{In vitro biocompatibility evaluation}

Fig. 3 shows the MTT cytotoxicity results of the porous Ti-10Mo alloy extracts for 1, 2, 3, and 7 days compared with those of the $\mathrm{CP} \mathrm{Ti}$ and $\mathrm{Ti}-6 \mathrm{Al}-4 \mathrm{~V}$ alloy extracts (commonly used in clinical practice), as well as the control (cultured by DMEM directly). The data are expressed as the CVR, and the control group has a CVR of $100 \%$, which is accepted as a reference in determining the CVR of specimens $[40,41]$. As shown in Fig. 3, the average CVR of all the experimental specimens is above $99 \%$. According to ISO 10993-5 [34], the cytotoxicity grade of these Ti alloys for MC3T3-E1 cells is $0-1$. The porous $\mathrm{Ti}-$ 10 Mo alloy exhibited a slightly higher average CVR value than the $\mathrm{CP} \mathrm{Ti}$ and $\mathrm{Ti}-6 \mathrm{Al}-4 \mathrm{~V}$, but there were no statistically significant differences among them $(P>0.05)$.

The nuclear staining was used to evaluate the number of the adhered cells on materials' surface at early stage. Fig. 4 shows the adhered MC3T3-E1 cells on the surfaces of porous $\mathrm{Ti}-10 \mathrm{Mo}$, Ti- $6 \mathrm{Al}-4 \mathrm{~V}$, and $\mathrm{CP}-\mathrm{Ti}$ at 1 and $4 \mathrm{~h}$. It can be seen that very few MC3T3-E1 cells adhered on the surfaces of each alloy in the early period of $1 \mathrm{~h}$. With the incubation time extended to $4 \mathrm{~h}$, there were more cells with well adhesions. Compared with Ti-6Al-4V and CP$\mathrm{Ti}$, there are more cells adhered on the surface of the

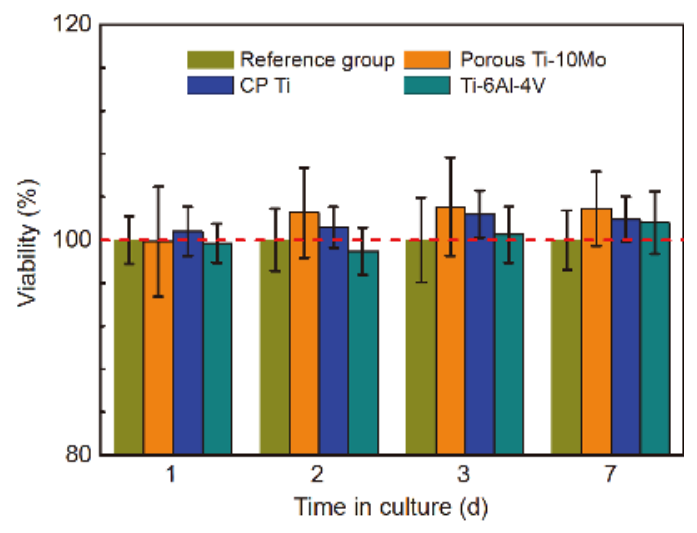

Figure 3 Effect of extracts of porous Ti-10Mo, CP Ti and Ti-6Al-4V alloy on viability of MC3T3-E1 cells at specific times of 1, 2, 3 and 7 days.

porous $\mathrm{Ti}-10 \mathrm{Mo}$ alloys, but there were no statistically significant differences among them $(P>0.05)$. This result demonstrates that all of these alloys have good cytocompatibility. The more adhered MC3T3-E1 cells on the porous Ti-10Mo alloy in the earlier stage also provide the opportunity for further observation of cell proliferation.

The cell proliferation on the surface of the porous Ti$10 \mathrm{Mo}$, dense $\mathrm{CP} \mathrm{Ti}$ and $\mathrm{Ti}-6 \mathrm{Al}-4 \mathrm{~V}$ alloys after culturing for different periods $(1,2$, and 3 days) was observed by fluorescence microscopy (Fig. 5). It can be seen that there was no significant difference of the cytoskeleton structure (green) observed among the three groups, which implied that cells could grow normally on the porous $\mathrm{Ti}-10 \mathrm{Mo}$ alloy as well as on that of CP-Ti and Ti-6Al-4V. Additionally, it can be seen that there were only a few nuclei on the surface of the porous Ti-10Mo alloy (Fig. 5a) after one day culture. With prolongation of culture time, the number of nuclei increased significantly (Fig. $5 \mathrm{~d}$ and g). 

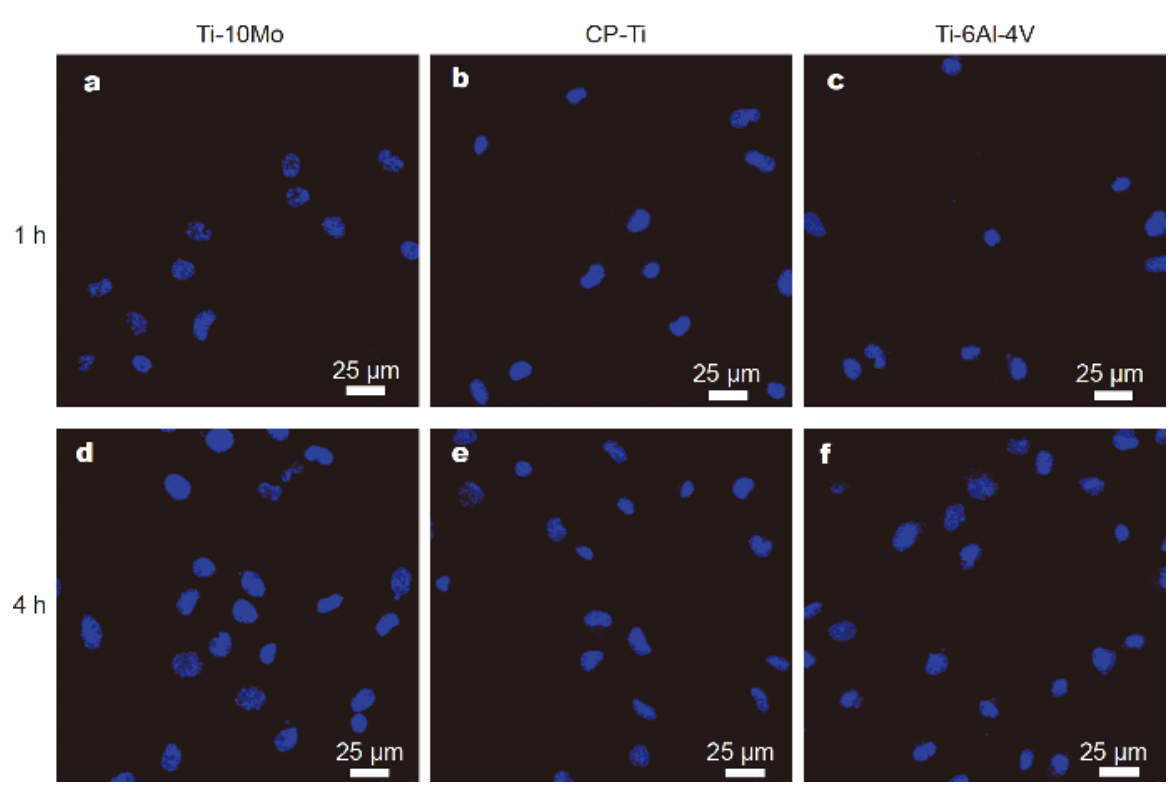

Figure 4 Images of MC3T3-E1 cells adhesion on surfaces of porous Ti-10Mo (a, d), CP-Ti (b, e), and Ti-6Al-4V (c, f) at 1 and $4 \mathrm{~h}$, respectively. Blue dot represents the nucleus of cell after staining by DAPI.


Figure 5 Quantity and morphology of MC3T3-E1 cultured on Ti-10Mo alloy of 63.4\% porosity, cast CP-Ti and Ti-6Al-4V at different times. Cell cytoskeleton (green) and nuclei (blue) were stained by phalloidin and DAPI, respectively.

After three days culture, there are more cells on the surface of the porous Ti-10Mo alloys than that on the surface of $\mathrm{CP}-\mathrm{Ti}$ and $\mathrm{Ti}-6 \mathrm{Al}-4 \mathrm{~V}$, which indicated that the porous structure might even promote cell growth. These results demonstrate that the porous Ti-10Mo alloy had no cytotoxic effect on MC3T3-E1 cells, which is consistent with the MTT results.

The cell morphology of MC3T3-E1 cells grown in the interior of the porous Ti-10Mo alloy after culturing for specific periods of $1,2,3$ and 4 days and the cumulative Mo ion concentration in DMEM for 1, 2, 3, 5 and 7 days are described in the Figs S1 and S2 (Supplementary 

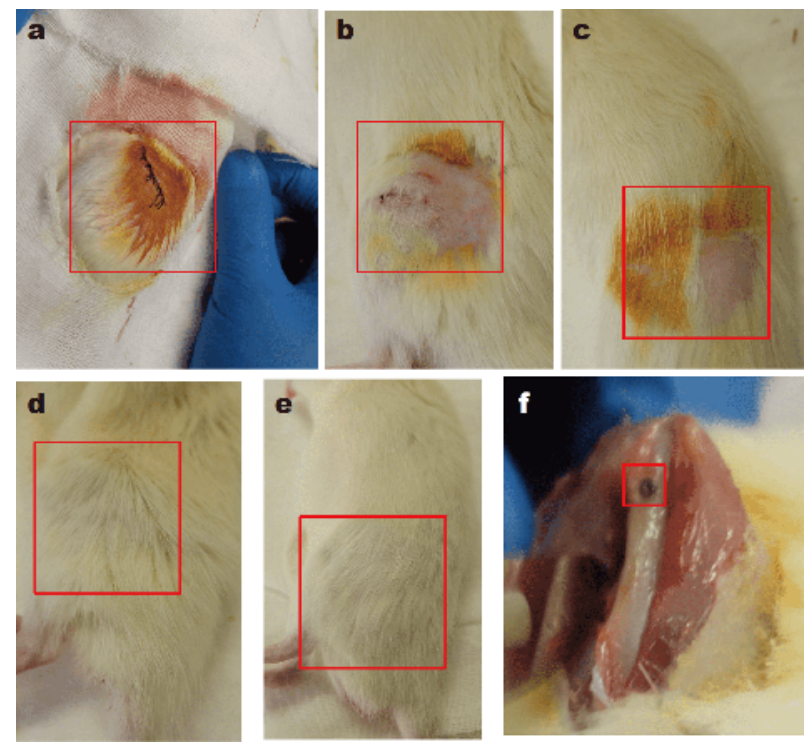

Figure 6 Appearance of implant position after operation (a), 2 weeks (b), 4 weeks (c), 8 weeks (d), 16 weeks (e) and implants surface condition after 2 weeks (f).

information), respectively. The results showed that with the prolongation of culture time, the cells were connected together and filled the pores gradually. The amount of released Mo ions increased slightly at the first five days, but it was barely increasing afterwards.

The in vitro cytotoxicity of an implant material is dependent not only on the toxicity of its alloying elements but also its corrosion resistance. In the present study, $\mathrm{Ti}$ $10 \mathrm{Mo}$ has lower Mo content than Ti-15Mo alloy (used clinically since 1998), which means the ions release from Ti-10Mo alloy may be less when implanted into the human body. That makes Ti-10Mo alloy have higher safety than Ti-15Mo alloy in the practical clinic application. Additionally, it has been demonstrated that the corrosion resistance of Ti-Mo alloys is superior to those of $\mathrm{CP}-\mathrm{Ti}$ and $\mathrm{Ti}-6 \mathrm{Al}-4 \mathrm{~V}$ due to the spontaneously formed stable $\mathrm{TiO}_{2}-\mathrm{MoO}_{3}$ passive film on its surface [42-46]. This spontaneously formed oxide film can provide a bio-inert layer in the aggressive body fluids, effectively inhibiting the release of metal ions. This is also why the amount of releasing Mo ions is very small after seven days immersion. Furthermore, physical factors also play an essential role in determining the interaction between implant materials and surrounding tissues. Previous studies have demonstrated that the presence of pores facilitates the attachment of osteoblast-like cells $[7,46]$. In this study, the porous Ti-10Mo alloy exhibited a larger average pore size than those reported [7], which is expected to provide a large surface area for cells to interact on through pro-
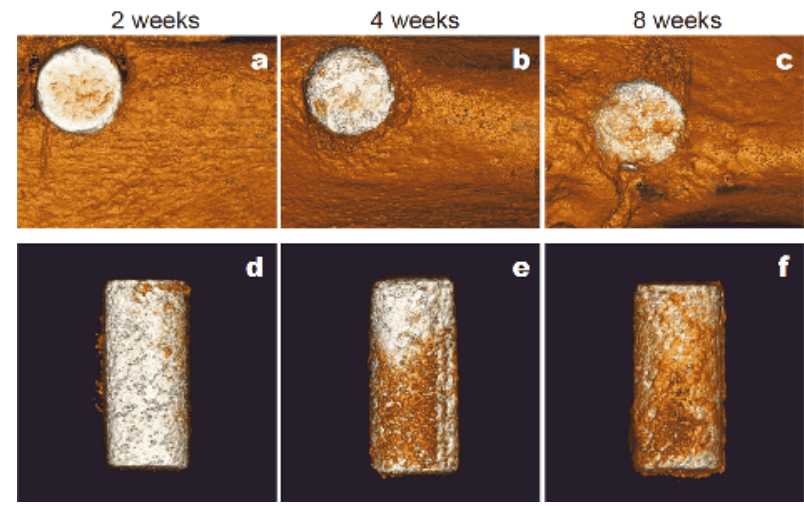

Figure 7 Micro-CT images of interfaces between porous Ti-10Mo alloy and bone $(\mathrm{a}-\mathrm{c})$ and surface of porous Ti-10Mo alloy at different times of implantation $(\mathrm{d}-\mathrm{f})$.

viding more mechanical anchoring sites, therefore facilitating the growth of cells. As a result, the porous Ti10 Mo alloy showed high cell viability during the MTT assay and excellent biocompatibility with MC3T3-E1 cells.

\section{In vivo osteointegration evaluation}

All animals recovered uneventfully after surgery and reached their allocated time point with no postoperative morbidity noted. Fig. 6 shows the appearance of the implant position and implants surface condition after the operation. It can be seen from Fig. 6a-e that no infections occurred on the implant site, and with prolongation of implantation time, new hair grew gradually. Also, no macroscopic signs of intolerance were observed for any of the implants in term of inflammation, hemorrhage, and necrosis (Fig. 6f, an example after two weeks implantation).

Micro-CT analysis was performed on the porous Ti$10 \mathrm{Mo}$ alloys after 2,4 and 8 weeks' implantation to discover the presence of any possible defects or gaps, and the bonding around the implant (Fig. 7). It can be seen that there was a gap between the bone and implant after implantation for 2 weeks (Fig. 7a). As time increased, this gap decreased gradually and disappeared after 8 weeks (Fig. 7c). To obtain more information about the bone ingrowth onto the porous $\mathrm{Ti}-10 \mathrm{Mo}$ alloy, high-resolution images of the new bone formed on the surface of the implant were taken, as shown in Fig. $7 \mathrm{~d}-\mathrm{f}$. It can be seen that new bone started to grow on the implant surface after implantation for 2 weeks. With an increase in the implantation time, the amount of new bone increased significantly, and the implant was surrounded by new bone after 8 weeks of implantation (Fig. 7f). 

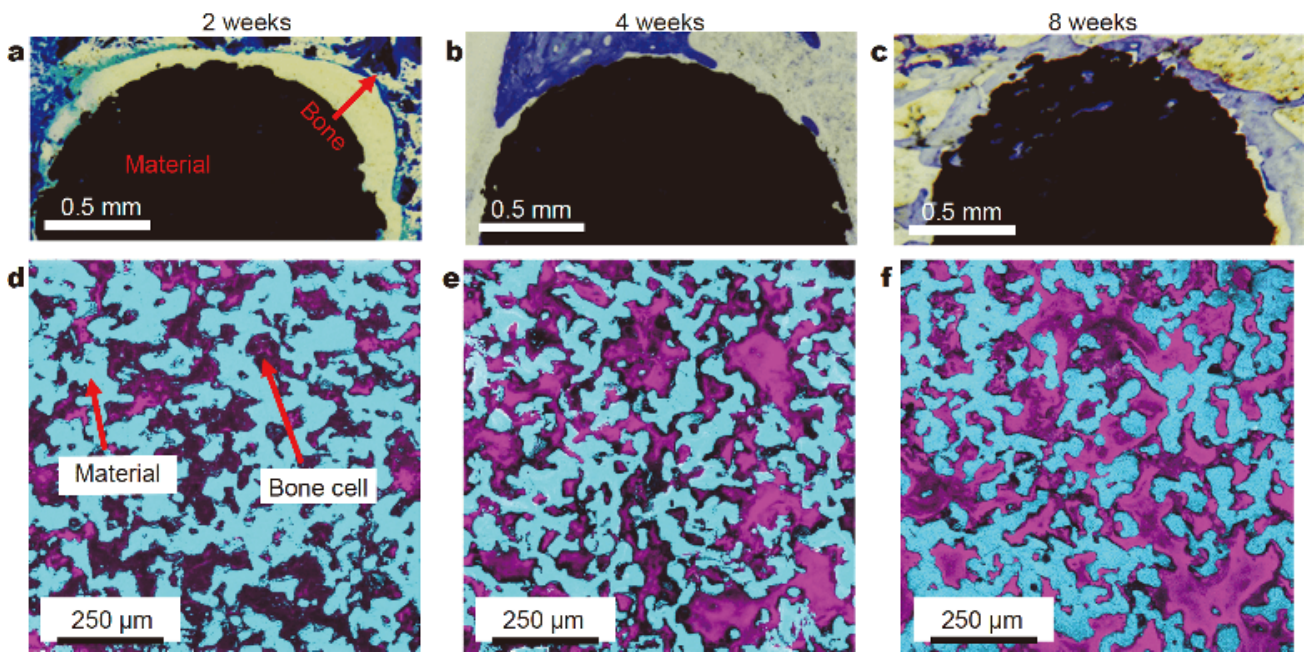

Figure 8 Histological section of porous Ti-10Mo alloy implant at different times of implantation: (a-c) optical micrographs, (d-f) fluorescence micrographs.

Histological evaluation at the bone-implant interface was performed to evaluate the osteointegration after implantation for 2, 4, and 8 weeks. Fig. 8 shows the histological section images of the porous $\mathrm{Ti}-10 \mathrm{Mo}$ specimens at different weeks of implantation. Signs of osteoid-like new bone formation were observed after 2 weeks (Fig. 8a and $\mathrm{d}$ ). The blue regions surrounding the implant area represent the newly formed osteoid, indicating noncytotoxicity of the implant. However, only a small amount of new bone formed surrounding the implant, with a gap between the implant and new bone (Fig. 8a, which is consistent with the micro-CT results. With an increase in the implantation time, the amount of newly formed bone gradually increased, as shown in Fig. $8 \mathrm{~b}$ and c. The newly formed bone almost surrounded the implant with only a few visible gaps after 8 weeks of implantation (Fig. 8c). Similar results were obtained inside the porous structure by fluorescence microscopy, as shown in Fig. $8 \mathrm{~d}$ and e. After 2 weeks' implantation, newly formed bone started to grow in the pores (Fig. 8a). With an increase in the implantation time to 4 weeks, the newly formed bone inside the pores increased (Fig. 8e). The pores of the scaffolds were almost filled with newly formed bone after 8 weeks of implantation (Fig. 8f), indicating excellent in vivo osteointegration.

Further analysis of the bone-tissue integration was carried out using push-out testing, and the load-displacement curves are shown in Fig. 9. The bonding strength between the porous Ti-10Mo alloy and bone increased over time from $46.6 \mathrm{~N}$ after 2 weeks to $176.4 \mathrm{~N}$ after 8 weeks. In addition, the bonding strength after 16

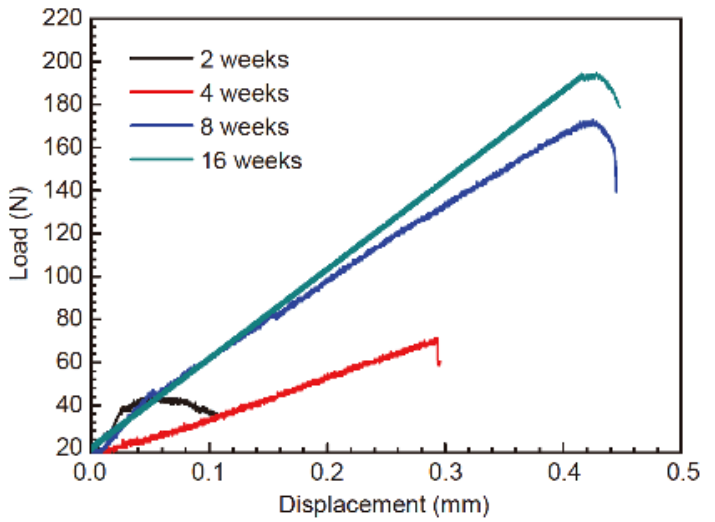

Figure 9 Peak load of push-out testing at different times.

weeks of implantation was measured as $193.3 \mathrm{~N}$. It can be seen that the bonding strength between implant and bone only increased slightly from $176.4 \mathrm{~N}$ after 8 weeks' implantation to $193.3 \mathrm{~N}$ after 16 week's implantations, which means that the new bone regeneration was almost complete after 8 weeks of implantation. Compared with dense Ti-6Al-4V [47], the time of new bone regeneration for the porous Ti-10Mo alloy is much faster (24 weeks for dense Ti-6Al-4V and 8 weeks for porous Ti-10Mo alloy), indicating that the porous Ti-10Mo alloy has better osteogenic ability. This is mainly because porous metal materials have the ability to provide biological anchorage for surrounding bone tissues and greater contact area at the implant-bone interface.

The excellent in vivo osteointegration of the porous Ti$10 \mathrm{Mo}$ alloy in this study likely resulted from both the 
lower elastic modulus and the open-cell porous structure. It is believed that a low elastic modulus benefits new bone formation in cancellous bone [48]. In the present study, the elastic modulus of the porous Ti-10Mo alloy with $63.4 \%$ porosity was about $2.9 \mathrm{GPa}$, which is significantly lower than that of solid Ti-alloy reported in the literature, such as $65 \mathrm{GPa}$ for solid Ti-7.5Mo [48], 70 GPa for solid Ti-13Nb-13Zr [49], and $110 \mathrm{GPa}$ for solid Ti-6Al-4V and CP-Ti. The lower elastic modulus of the porous $\mathrm{Ti}$ $10 \mathrm{Mo}$ alloy promoted new bone formation. This is consistent with the results reported by Lin et al. [48], who demonstrated that the new bone formation surrounding the solid Ti-7.5Mo ( $65 \mathrm{GPa}$ ) increased over time, while the new bone formation surrounding solid Ti-6Al-4V $(110 \mathrm{GPa})$ decreased over time. Moreover, as mentioned above, a high open pore volume allows more body fluids to be transported through the interconnected pores, which subsequently accelerates the healing process by allowing tissue to grow inside the implants and improves the biological fixation [50]. A similar influence of porosity on bone ingrowth has also been reported in porous bioactive Ti implants [51,52]. Hence, it can be concluded that the porous Ti-10Mo scaffolds fabricated by a simple powder metallurgical method exhibited low elastic modulus, high compressive yield strength, and excellent in vitro biocompatibility and in vivo osteointegration, and so can be anticipated as an attractive orthopedic implant alloy.

\section{CONCLUSIONS}

Porous Ti-10Mo alloys with porosities ranging from $\sim 50 \%$ to $\sim 67 \%$ and average pores size from 70 to $381 \mu \mathrm{m}$ were fabricated successfully. The fabricated Ti-10Mo alloys showed a typical Widmanstäten microstructure, and achieved wide properties with elastic modulus of 6.4-1.7 GPa and compression yield strength of 248.2-76.9 MPa. The porous Ti-10Mo alloys displayed no adverse effects on cell behavior, and the cytotoxicity level was ranked $0-1$ grade. In addition, the porous Ti-10Mo alloys exhibited excellent biocompatibility and osteointegration, and the bonding strength between the porous Ti-10Mo alloy and bone increased over time from $46.6 \mathrm{~N}$ after 2 weeks to $176.4 \mathrm{~N}$ after 8 weeks and $193.3 \mathrm{~N}$ after 16 weeks of implantation. This porous Ti-10Mo alloy fabricated by powder metallurgy can be considered an attractive orthopedic implant material by virtue of its excellent mechanical properties, in vitro biocompatibility, and in vivo osteointegration.

Received 16 November 2018; accepted 10 January 2019; published online 30 January 2019
1 Geetha M, Singh AK, Asokamani R, et al. Ti based biomaterials, the ultimate choice for orthopaedic implants-A review. Prog Mater Sci, 2009, 54: 397-425

2 Long M, Rack HJ. Titanium alloys in total joint replacement-a materials science perspective. Biomaterials, 1998, 19: 1621-1639

3 Banerjee D, Williams JC. Perspectives on titanium science and technology. Acta Mater, 2013, 61: 844-879

4 Niinomi M, Nakai M, Hieda J. Development of new metallic alloys for biomedical applications. Acta Biomater, 2012, 8: 3888-3903

5 Nune KC, Li S, Misra RDK. Advancements in three-dimensional titanium alloy mesh scaffolds fabricated by electron beam melting for biomedical devices: mechanical and biological aspects. Sci China Mater, 2018, 61: 455-474

6 Aksakal B, Yildirim ÖS, Gul H. Metallurgical failure analysis of various implant materials used in orthopedic applications. J Fail Anal Preven, 2004, 4: 17-23

7 Chang B, Song W, Han T, et al. Influence of pore size of porous titanium fabricated by vacuum diffusion bonding of titanium meshes on cell penetration and bone ingrowth. Acta Biomater, 2016, 33: 311-321

8 Ho WF, Ju CP, Chern Lin JH. Structure and properties of cast binary Ti-Mo alloys. Biomaterials, 1999, 20: 2115-2122

9 Zhao X, Niinomi M, Nakai M, et al. Beta type Ti-Mo alloys with changeable Young's modulus for spinal fixation applications. Acta Biomater, 2012, 8: 1990-1997

10 González JEG, Mirza-Rosca JC. Study of the corrosion behavior of titanium and some of its alloys for biomedical and dental implant applications. J Electroanal Chem, 1999, 471: 109-115

11 Kumar S, Narayanan TSNS. Corrosion behaviour of Ti-15Mo alloy for dental implant applications. J Dentistry, 2008, 36: 500-507

12 Yan M, Qian M, Kong C, et al. Impacts of trace carbon on the microstructure of as-sintered biomedical Ti-15Mo alloy and reassessment of the maximum carbon limit. Acta Biomater, 2014, 10: 1014-1023

13 ATI $15 \mathrm{Mo}^{\mathrm{TM}}$ Titanium alloy technical data sheet. ATI Allvac, Monroe, NC

14 Jablokov V, Nutt M, Richelsoph M, et al. The application of Ti$15 \mathrm{Mo}$ beta titanium alloy in high strength structural orthopaedic applications. J ASTM Int, 2005, 2: 13033

15 Lin JH, Ju CP, Ho WF, inventors, J.H. Chern, assignee. Biocompatible low modulus titanium alloy for medical implant. United States patent, 6409852, 2002 Jun. 25

16 Disegi J. Wrought titanium-15\% molybdenum implant material. SYNTHES Instruments and Implants, Second Edition. 2009

17 Li Y, Wong C, Xiong J, et al. Cytotoxicity of titanium and titanium alloying elements. J Dent Res, 2010, 89: 493-497

18 Zhou YL, Luo DM. Microstructures and mechanical properties of Ti-Mo alloys cold-rolled and heat treated. Mater Charact, 2011, 62: 931-937

19 Cremasco A, Messias AD, Esposito AR, et al. Effects of alloying elements on the cytotoxic response of titanium alloys. Mater Sci Eng-C, 2011, 31: 833-839

20 Lee EB, Han MK, Kim BJ, et al. Effect of molybdenum on the microstructure, mechanical properties and corrosion behavior of Ti alloys. Int J Mater Res, 2014, 105: 847-853

21 Liu Y, Zheng Y, Hayes B. Degradable, absorbable or resorbablewhat is the best grammatical modifier for an implant that is eventually absorbed by the body? Sci China Mater, 2017, 60: 377391 
22 Wang X, Xu S, Zhou S, et al. Topological design and additive manufacturing of porous metals for bone scaffolds and orthopaedic implants: A review. Biomaterials, 2016, 83: 127-141

23 Vandendolder J, Farber E, Spauwen P, et al. Bone tissue reconstruction using titanium fiber mesh combined with rat bone marrow stromal cells. Biomaterials, 2003, 24: 1745-1750

24 Marin E, Fusi S, Pressacco M, et al. Characterization of cellular solids in Ti6Al4V for orthopaedic implant applications: Trabecular titanium. J Mech Behav BioMed Mater, 2010, 3: 373-381

25 Zardiackas LD, Parsell DE, Dillon LD, et al. Structure, metallurgy, and mechanical properties of a porous tantalum foam. J Biomed Mater Res, 2001, 58: 180-187

26 Gao Z, Li Q, He F, et al. Mechanical modulation and bioactive surface modification of porous Ti-10Mo alloy for bone implants. Mater Des, 2012, 42: 13-20

27 Li S, Li X, Hou W, et al. Fabrication of open-cellular (porous) titanium alloy implants: osseointegration, vascularization and preliminary human trials. Sci China Mater, 2018, 61: 525-536

28 Correa VL, Garza KM, Murr LE. Vascularization in interconnected $3 \mathrm{D}$ printed Ti-6Al-4V foams with hydrogel matrix for biomedical bone replacement implants. Sci China Mater, 2018, 61: 565-578

29 Xie F, He X, Lu X, et al. Preparation and properties of porous Ti10Mo alloy by selective laser sintering. Mater Sci Eng-C, 2013, 33: 1085-1090

30 Xie F, He X, Lv Y, et al. Selective laser sintered porous Ti-(4-10) Mo alloys for biomedical applications: Structural characteristics, mechanical properties and corrosion behaviour. Corros Sci, 2015, 95: $117-124$

31 Xie FX, He XB, Cao SL, et al. Structural characterization and electrochemical behavior of a laser-sintered porous Ti-10Mo alloy. Corros Sci, 2013, 67: 217-224

32 Wong KC, Scheinemann P. Additive manufactured metallic implants for orthopaedic applications. Sci China Mater, 2018, 61: $440-454$

$33 \mathrm{Xu} \mathrm{W}, \mathrm{Lu} \mathrm{X}$, Zhang B, et al. Effects of porosity on mechanical properties and corrosion resistances of PM-fabricated porous Ti10Mo alloy. Metals, 2018, 8: 188-201

34 ISO 10993-5: 1999. Biological evaluation of medical devices-part 5: tests for cytotoxicity: in vitro methods. ANSI/AAMI, Arlington, VA

35 Wen CE, Yamada Y, Shimojima K, et al. Novel titanium foam for bone tissue engineering. J Mater Res, 2002, 17: 2633-2639

36 Kawai N, Niwa S, Sato M, et al. Bone formation by cells from femurs cultured among three-dimensionally arranged hydroxyapatite granules. J Biomed Mater Res, 1997, 37: 1-8

37 Krishna BV, Bose S, Bandyopadhyay A. Low stiffness porous $\mathrm{Ti}$ structures for load-bearing implants. Acta Biomater, 2007, 3: 9971006

38 Cameron HU, Pilliar RM, Macnab I. The rate of bone ingrowth into porous metal. J Biomed Mater Res, 1976, 10: 295-302

39 Ryan GE, Pandit AS, Apatsidis DP. Porous titanium scaffolds fabricated using a rapid prototyping and powder metallurgy technique. Biomaterials, 2008, 29: 3625-3635

40 Li Y, Wen $\mathrm{C}$, Mushahary $\mathrm{D}$, et al. $\mathrm{Mg}-\mathrm{Zr}-\mathrm{Sr}$ alloys as biodegradable implant materials. Acta Biomater, 2012, 8: 3177-3188
$41 \mathrm{Xu} \mathrm{W}, \mathrm{Li} \mathrm{M}$, Wen $\mathrm{C}$, et al. The mechanical properties and in vitro biocompatibility of PM-fabricated Ti-28Nb-35.4Zr alloy for orthopedic implant applications. Materials, 2018, 11: 531

42 Oliveira NTC, Guastaldi AC. Electrochemical behavior of Ti-Mo alloys applied as biomaterial. Corros Sci, 2008, 50: 938-945

43 Zhou YL, Luo DM. Corrosion behavior of Ti-Mo alloys cold rolled and heat treated. J Alloys Compd, 2011, 509: 6267-6272

44 Chen J, Paetzell E, Zhou J, et al. Osteoblast-like cell ingrowth, adhesion and proliferation on porous Ti-6Al-4V with particulate and fiber scaffolds. Mater Sci Eng-C, 2010, 30: 647-656

$45 \mathrm{Xu} \mathrm{W}, \mathrm{Lu} \mathrm{X}$, Wang $\mathrm{LN}$, et al. Mechanical properties, in vitro corrosion resistance and biocompatibility of metal injection molded Ti-12Mo alloy for dental applications. J Mech Behav BioMed Mater, 2018, 88: 534-547

46 Huang $\mathrm{HH}, \mathrm{Wu} \mathrm{CP}$, Sun YS, et al. Surface nanoporosity of $\beta$-type $\mathrm{Ti}-25 \mathrm{Nb}-25 \mathrm{Zr}$ alloy for the enhancement of protein adsorption and cell response. Surf Coatings Tech, 2014, 259: 206-212

47 Okazaki Y, Nishimura E, Nakada H, et al. Surface analysis of Ti$15 \mathrm{Zr}-4 \mathrm{Nb}-4 \mathrm{Ta}$ alloy after implantation in rat tibia. Biomaterials, 2001, 22: 599-607

48 Lin DJ, Chuang CC, Chern Lin JH, et al. Bone formation at the surface of low modulus Ti-7.5Mo implants in rabbit femur. Biomaterials, 2007, 28: 2582-2589

49 Majumdar P, Singh SB, Chakraborty M. The role of heat treatment on microstructure and mechanical properties of $\mathrm{Ti}-13 \mathrm{Zr}-13 \mathrm{Nb}$ alloy for biomedical load bearing applications. J Mech Behav BioMed Mater, 2011, 4: 1132-1144

50 Muller D, Chim H, Bader A, et al. Vascular guidance: microstructural scaffold patterning for inductive neovascularization. Stem Cells Int, 2011, 2011: 1-6

51 Bandyopadhyay A, Espana F, Balla VK, et al. Influence of porosity on mechanical properties and in vivo response of Ti6Al4V implants. Acta Biomater, 2010, 6: 1640-1648

52 Caparrós C, Guillem-Martí J, Molmeneu M, et al. Mechanical properties and in vitro biological response to porous titanium alloys prepared for use in intervertebral implants. J Mech Behav BioMed Mater, 2014, 39: 79-86

Acknowledgements This work was supported by the Fundamental Research Funds for the Central Universities (FRF-GF-17-B39). Wen C acknowledges the financial support for this research by the National Health and Medical Research Council (NHMRC), Australia through project grant (GNT1087290).

Author contributions $\mathrm{Lu} \mathrm{X}$ and $\mathrm{Li} \mathrm{Z}$ designed the experiments; Xu W and Liu Z performed the experiments; Xu W, Liu Z, and Tian J performed the data analysis; $\mathrm{Xu} W$ and Liu $Z$ wrote the paper with support from Lu X and Li Z; Chen G, Liu B, Qu X, and Wen C contributed to the theoretical analysis. All authors contributed to the general discussion.

Conflict of interest The authors declare that they have no conflict of interest.

Supplementary information Supporting information is available in the online version of the paper. 

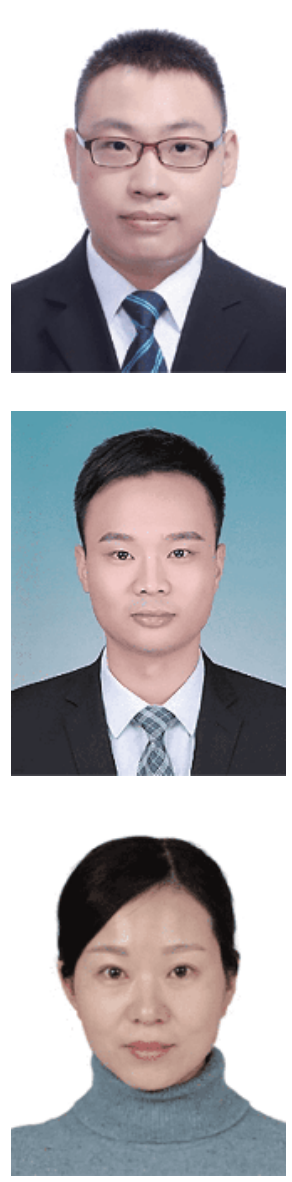

Wei Xu received his bachelor's and master's degree in materials science and engineering from Heilongiiang University of Science and Technology in 2014 and University of Science \& Technology Beijing in 2017, respectively. Then he continued his study as a PhD candidate in Prof. Xuanhui Qu's and Xin Lu's Lab in University of Science \& Technology Beijing. His research interest mainly focuses on the biomedical metallic materials and near-net-shape process (selective laser sintering).

Zhuo Liu is a PhD candidate in Beihang University, and he is also an exchange student in Beijing Institute of Nanoenergy and Nanosystems. His current research interest focuses on biomaterials, self-powered medical devices, and biomechanics.

Xin Lu is a professor at Beijing Advanced Innovation Center for Materials Genome Engineering, Institute for Advanced Materials and Technology, University of Science and Technology Beijing. Her research interest mainly focuses on powder metallurgy of titanium-based alloy, including preparation and characteristics of alloy powders, titanium near-net-shape process (powder injection molding, selective laser sintering) and fast sintering techniques (spark plasma sintering), design and fabrication of new biomedical titanium alloys.

\section{粉末冶金制备的多孔Ti-10Mo合金用于促进骨修复的研究}

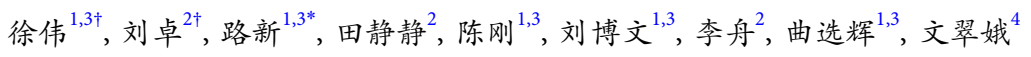

摘要 本文中, 我们以元素粉末为原料, 采用粉末冶金造孔剂法制备了多孔Ti-10Mo合金, 系统探讨了所制备的多孔Ti-10Mo合金的孔隙特 征、显微组织、力学性能、体外生物相容性及体内骨整合能力. 结果表明, 随着造孔剂含量的增加(碳酸氢铵), 在 $1300^{\circ} \mathrm{C}$ 下烧结的多孔Ti$10 \mathrm{Mo}$ 合金均由魏氏体组织组成. 所制备的 Ti-10Mo合金的孔隙率与平均孔尺寸能够分别控制在 50.8\%-66.9\%与70.1-381.4 $\mu \mathrm{m}$. 孔隙率为 $63.4 \%$ 的 $\mathrm{Ti}-10 \mathrm{Mo}$ 合金具有最适合植入应用的力学性能, 其弹性模量为 $2.9 \mathrm{GPa}$, 抗压屈服强度为 $127.5 \mathrm{MPa}$. 在体外, Ti-10Mo合金浸提液 对细胞增殖没有不良影响. 细胞在浸提液中的存活率高于对照组, 表明合金无毒性并且具有良好的生物学特征. 在体内, 植入 8 周后合金周 围被新生骨包围, 并且植入部分未见明显炎症. 随着植入时间由 2 周增加到 8 周, 多孔Ti-10Mo合金的骨结合强度从 $46.6 \mathrm{~N}$ 增加到 $176.4 \mathrm{~N}$. 适 合的力学性能以及良好的体外生物相容性和体内骨整合性使粉末冶金法制备的多孔Ti-10Mo成为一种具有吸引力的骨科植入合金. 